\title{
A Expressão 'Daí' na Fala dos Jnformantes Curitibanos: um estudo com base nos dados do Atlas Linguístico do Brasil
}

\author{
Dayse de Souza Lourenço SIMÕES* \\ Josyelle Bonfante CURTI** \\ Mariana Spagnolo MARTINS***
}

\footnotetext{
* Doutora (2019) em Estudos da Linguagem pela Universidade Estadual de Londrina (UEL). Contato: dayse.lourenco1990@gmail.com.

** Mestra (2019) em Estudos da Linguagem pela Universidade Estadual de Londrina (UEL). Contato: joosy.curtii@gmail.com.

*** Mestra (2019) em Estudos da Linguagem pela Universidade Estadual de Londrina (UEL). Contato: mariana.spagnolo@hotmail.com.
}

\section{Resumo:}

Este estudo procura identificar as circunstâncias de uso do item dai na fala de informantes de Curitiba e tem como corpus dados de entrevistas do Projeto Atlas Linguístico do Brasil (ALiB). Esta pesquisa justifica-se pelo fato de, em localidades do Sul brasileiro, o uso do daí ser frequente em contextos diferentes dos estabelecidos pelas gramáticas, isto é, como advérbio de lugar ou de tempo. Para a constituição da fundamentação teórica, utilizamos estudos sobre o processo de gramaticalização e estratificamos os resultados baseados na Teoria da Variação Linguística, na qual observamos os dados de acordo com as variáveis diassexual, diageracional e diastrática. Portanto, esta pesquisa tem por finalidade: (i) verificar, na fala dos informantes de Curitiba do corpus do ALiB, o emprego da expressão daí como advérbio e como outras classes gramaticais ou discursivas; (ii) analisar cada emprego segundo as variáveis extralinguísticas; e (iii) verificar se há fatores linguísticos intervindo no uso da expressão daí. Assim, constatamos que o daí revelou-se como marca discursiva na fala de mulheres idosas e com nível superior de escolaridade, o que pode indicar que a mudança não se consolidou, mas a frequência do seu uso permanece no nível da variação diagenérica e diastrática.

\section{Palavras-chave:}

Uso dao dai. Atlas Linguístico do Brasil. Curitiba.

Signum: Estudos da Linguagem, Londrina, v. 22, n. 2, p. 72-91, ago. 2019 


\section{A Expressão 'Dai' na Fala dos Informantes Curitibanos: \\ um estudo com base nos dados do Atlas Linguístico do Brasil}

Dayse de Souza Lourenço Simões; Josyelle Bonfante Curti; Mariana Spagnolo Martins

\section{INTRODUÇão}

O termo dai é a contração da preposição DE com o advérbio AÍ; segundo Cunha (1994), data do século XIV, sob as formas $d y$, di e $d j$. O interesse pelo tema devese à utilização do dai em contextos diferentes daqueles em que: (i) indica lugar, como em "Saia já dâ" (desse lugar); ou (ii) a decorrência de tempo, como em "Daí (= em seguida) saiu de casa". Embora para os estudos morfológicos o daí seja a junção da preposição $d e+a i=$ advérbio de tempo ou de lugar, no discurso de alguns curitibanos essa expressão recebe outras categorias de uso, aparecendo com funções diferentes das estabelecidas pelas gramáticas. Trata-se da gramaticalização, a qual, segundo Tavares (2006, p. 266267), representa

uma evolução de um estado de maior autonomia e estabilidade de significados para um estado de menor autonomia e maior instabilidade: à medida que os itens lexicais sofrem gramaticalização, emergem significados de natureza abstrata e genérica, mais adaptáveis a contextos de uso diversificados.

De acordo com a autora, o processo de gramaticalização do daí é compreendido, conforme a Linguística Textual, como um marcador sequencial do texto que pode ser configurado como um sequenciador de retroação (uso anafórico, retomando algo já dito) ou de propulsão (conduzindo a atenção do interlocutor para o que ainda será dito no texto), ambos fatores importantes para a coesão textual. Igualmente, Risso (2006 apud SANTOS, 2014, p. 196) indica que o dai se configura como um marcador sequencial que apresenta o traço sequenciador tópico, operando na microestrutura textual e fazendo progredir o tema de forma seriada e articulada ou, como diz Koch (2015), estabelecendo, entre os segmentos do texto, diversos tipos de relação semântica ou pragmático-discursiva. Em outras palavras, o daí, enquanto marcador essencialmente conversacional, permite uma continuidade tópica, apoiada na inserção ou na retomada de ideias e de argumentos, atuando na progressão textual e articulando o texto e seus conceitos.

Nesse cenário de possibilidades, esta pesquisa objetiva identificar o uso da expressão daí na fala dos informantes de Curitiba, procurando averiguar em que 
circunstância tal expressão é empregada e quais fatores linguísticos e extralinguísticos podem atuar sobre o maior ou menor uso desse item em contextos diferentes dos estabelecidos pela Gramática Normativa.

Para tanto, contamos com os dados coletados pelo Projeto Atlas Linguístico do Brasil (ALiB), o qual envolve 15 instituições universitárias brasileiras e tem sua sede na Universidade Federal da Bahia (UFBA). O projeto objetiva descrever as diferenças diatópicas, diastráticas, diageracionais e diafásicas; proporcionar material aos estudiosos da língua; traçar áreas dialetais; construir um acervo de dados capaz de auxiliar a elaboração de dicionários e "contribuir para o entendimento da língua portuguesa no Brasil como instrumento social de comunicação diversificado, possuidor de várias normas de uso, mas dotado de uma unidade sistêmica" (COMITÊ NACIONAL DO PROJETO ALIB, 2001).

Os dados do ALiB englobam 250 pontos de investigação, fixados segundo a densidade demográfica, incluindo as capitais dos Estados - exceto Palmas e Brasília, devido à recente fundação, perfazendo um total de 1.100 informantes, como assevera Cardoso (2006), estratificados segundo o sexo, a faixa etária (18 a 30 e 50 a 65 anos) e a escolaridade. Desse modo, fundamentamo-nos, também, na Teoria da Variação Linguística, com a intenção de colaborar com a descrição e a análise das características do falar curitibano, tomando como objeto de análise a fala coletada em oito entrevistas realizadas na capital paranaense.

\section{Um Pouco sobre Gramaticalização}

A partir da observação do emprego do daí no corpus coletado pelo ALiB em Curitiba, com funções distintas das previstas ou estabelecidas pela Gramática Normativa, abrimos espaço para o estudo da gramaticalização ${ }^{1}$ que, de forma resumida, diz respeito a quando um item lexical passa a assumir, em alguns casos, uma nova posição gramatical, ou quando um item gramatical se torna ainda mais gramatical.

Recorremos aos estudos de Vitral (1996), de Castilho (1997a, 1997b), de Tavares (2002, 2006) e de Gonçalves, Lima-Hernandes e Casseb-Galvão (2007), sendo o embasamento teórico amparado em Vitral, Castilho e Gonçalves, Lima-Hernandes e Casseb-Galvão. Em Tavares (2002, 2006), que serviu de pautou a descrição e a análise dos dados, além de conceitos sobre esse processo, observamos, especificamente, o item daí sob a óptica sociofuncionalista da língua.

De acordo com Castilho (1997b), a concepção modular da língua falada é constituída por processos de semanticização, discursivização e gramaticalização:

${ }^{1}$ [Do fr. Grammaticalisation.] S.f. No processo de mudança linguística, a passagem de um morfema que funciona como forma livre (q.v), ou como afixo derivacional, o marcador gramatical (FERREIRA, 1986). 
Em suma, os processos intuídos por tantos lingüistas do oral consistiram, do meu ponto de vista, na ativação de propriedades já contidas no léxico, de que resultariam as categorias discursivas (=processo de discursivização), gramaticais (=processo de gramaticalização) e semânticas (=processo de semanticização). Nesta perspectiva, o Léxico é dado como um componente lingüístico primitivo, no sentido de que ele não deriva de outas instâncias da língua (p. 109).

Tais processos criam os conjuntos de módulos da língua, uma espécie de organização linguística. Novamente, nas palavras do autor,

cada módulo será caracterizável por dispor de um conjunto de propriedades. Assim, a referenciação, a predicação, a dêixis, a foricidade, etc., são propriedades do módulo semântico. As classes, as relações que entre elas se estabelecem, as funções que essas classes assumem no enunciado, bem como sua representação fonológica, provêm das propriedades gramaticais. A organização tópica, a disposição dos tópicos em unidades discursivas, e os operadores da coesão textual podem ser postuladas como propriedades do discurso (1997b, p. 108).

Como o linguista exemplifica, as funções que as classes de palavras desempenham são definidas como pertencentes à gramática; desse modo, a mudança que uma classe pode vir a sofrer corresponde à gramaticalização, ou seja, quando um item lexical, que já é um item gramatical, torna-se ainda mais gramatical, assumindo outras categorias além daquelas já estabelecidas pela vertente normativa da língua.

Além disso, Castilho (1997a) afirma que a gramaticalização é também a ampliação dos limites de um morfema, cujo estatuto gramatical avança do léxico para a gramática, sendo este a transformação de um formato derivativo para o formato flexional. Compreendemos que, no processo de gramaticalização, um item lexical perde o seu significado e assume funções gramaticais de acordo com o uso da modalidade oral da língua.

Assim sendo, a gramaticalização é um processo de reelaboração da língua, sendo uma das formas mais comuns de observar as línguas de maneira geral, afinal, segundo Gonçalves, Lima-Hernandes e Casseb-Galvão (2007), não há gramática como produto acabado, mas, sim, uma constante gramaticalização. Ademais, assim como os autores consideram a gramaticalização um processo em constante mudança, Tavares (2002) compreende que a gramaticalização, assim como a gramática, é emergente, está sempre a caminho da constituição, mas nunca chega a constituir-se de fato, visto que as regras gramaticais não correspondem à demanda da língua falada, ao passo que a gramaticalização, de maneira simplificada, tem maior aceitação sobre a modalidade oral da língua.

O processo em destaque faz referência ao ciclo funcional de Givón, quando aponta uma motivação pragmático-discursiva dentre os estágios da gramaticalização. 
Givón (apud LOPES, 2008) apresenta um esquema de processos de regularização do uso da língua, tratando dos conceitos de Saussure na perspectiva diacrônica: ${ }^{2}$ Discurso $>$ Sintaxe $>$ Morfologia $>$ Zero. Em adaptação a esse ciclo, Vitral (1996), ao estudar a gramaticalização do item lexical você, desenvolve algo parecido com o que Givón apresentou. Para Vitral (1996), o processo de gramaticalização pode ser exemplificado como: item com significado lexical $>$ item gramatical $>$ clítico $>$ afixo $>$ flexional. De acordo com o autor, no processo de gramaticalização o item lexical sofre alterações tanto em sua estrutura quanto em sua funcionalidade.

A afirmativa de Vitral (1996) é explicada na terminologia de Gonçalves, LimaHernandes e Casseb-Galvão (2007), ao estratificarem a gramaticalização em três subprocessos:

A gramaticalização cinde-se em três subprocessos: fonologização (alterações no corpo fônico das palavras), morfologização (alterações que afetam o radical e os afixos) e sintaticização (alteração que afeta as categorias lexicais, os arranjos sintagmáticos e a atribuição de funções na sentença) (p. 16).

Além dos subprocessos, há duas formas de gramaticalização: ou ela é um processo, quando se dedica à análise de itens que já são gramaticais e tornam-se mais gramaticais, ou é um paradigma, quando a intenção é focalizar o estudo para observar como surgem as construções gramaticais e como elas são usadas. Também pode ser observada dentro das perspectivas diacrônica ${ }^{3}$ e da sincrônica, ${ }^{4}$ no caso do nosso objeto em estudo, dá, podendo entendê-lo como um paradigma, que está dentro da perspectiva diacrônica.

Para Hopper (1991 apud LOPES, 2008), um dos efeitos da gramaticalização é a persistência, isto é, uma forma lexical ou um elemento lexical pode ser retido por bastante tempo. Devido às suas herdeiras gramaticais, uma palavra sofre modificações ao longo do tempo, ou mesmo no modo como os sujeitos usam essas palavras no vocabulário cotidiano. A gramaticalização preocupa-se exatamente com essa transformação que a palavra sofre, por exemplo em decorrência do tempo, como no caso de você, em que os antigos usavam a expressão Vossa mercê, mas, com a adaptação, ou o uso popular da expressão, passou a ser mais utilizado o você. Temos, então, um caso de gramaticalização paradigmática com perspectiva diacrônica, pois a expressão você surgiu de Vossa mercê, e o uso por grande parte dos falantes, ou mesmo por uma questão de adaptação da língua, extinguiu a expressão antiga e a substituiu por uma nova.

\footnotetext{
${ }^{2}$ No decorrer deste estudo tratamos tais conceitos e a forma como Tavares (2002) utiliza esses métodos para analisar a pancronia, a gramaticalização no uso do dai como conector.

3 "A lingüística diacrônica estuda as relações entre termos sucessivos que se substituem uns aos outros no tempo" (SAUSSURE, 1995, p. 163).

4 “O objeto da lingüística sincrônica geral é estabelecer os princípios fundamentais de todo sistema idiossincrônico, os fatores constitutivos de todo estado de língua” (SAUSSURE, 1995, p. 117).
} 
Sobre o item lexical dai e suas várias funções contextuais, nossa análise volta-se para a gramaticalização desse item do ponto de vista da sintaticização, considerada em uma visão pancrônica, visto que, para Tavares (2002), a gramaticalização é um processo sempre em andamento, o que impossibilita o recorte estático de períodos de tempo eles possuem fronteiras indistintas, não podendo ser caracterizadas como fatias discretas e isoladas (TAVARES, 2006).

Tavares faz suas análises em uma perspectiva ampla em relação ao objeto em estudo, não apenas baseada na sincronia ou na diacronia, mas nas duas perspectivas, portanto, em uma visão pancrônica. Nessa última perspectiva, a autora analisa textos dos séculos XIII a XX, escritos em língua portuguesa, que têm aproximação com a fala. Os resultados obtidos em relação aos textos antigos foram baixos, pois apenas em um caso (no romance $A s$ Vinhas da Ira, de Steinbeck, 1940) houve um percentual considerável de ocorrências do daí.

Ao contrário, as análises feitas nos dados do VARSUL (Variação Linguística Urbana da Região Sul) indicaram um número expressivo de casos de gramaticalização do dai na fala dos informantes de Porto Alegre, de Florianópolis e de Curitiba.

Para Tavares (2006), são quatro os mecanismos que estão envolvidos no processo de mudança desse item: a metáfora (processo que se fundamenta numa relação de semelhança subentendida entre o sentido próprio e o figurado); a metonímia (a parte pelo todo); a reanálise (reorganização e mudanças de regras lineares); e a analogia (semelhança de particularidades ou funções). Esses conceitos estão empregados na gramaticalização e no processo de mudanças de cada forma gramatical transformada, seja por uma transformação de perspectiva sincrônica ou diacrônica.

A utilização do dai no falar dos curitibanos é frequente dentro de contextos diferentes. Para a morfologia, o dai é a junção da preposição de+aí= advérbio de tempo, mas, no discurso, essa expressão ganha outras categorias, isto é, passa a ser empregada com funções divergentes das quais as gramáticas estipulam. Ocorre, assim, a gramaticalização, que pode ser considerada sob a forma de paradigma ou de processo, podendo ser baseada na dicotomia saussuriana, na perspectiva sincrônica e diacrônica, e na perspectiva pancrônica - como vimos nos estudos de Tavares (2006).

Com base nas ocorrências do dai na fala dos informantes de Curitiba, segundo o banco de dados do ALiB, exploramos as várias funções que esse item lexical assume na fala cotidiana e observamos como a gramaticalização acontece em palavras (itens lexicais) que ganham formas e sentidos diversos.

A compreensão do item dai pode ser abordada por diferentes áreas, assim, observamos que nesta, em particular, tanto os estudos de variação linguística quanto os estudos dos articuladores textuais podem apresentar subsídios coerentes para o uso do dai na fala dos informantes analisados nesta pesquisa, já que o texto oral transforma-se em texto escrito e, possibilitando a realização do estudo. 
Dessa forma, podemos interpretar o item lexical que sofre o processo de gramaticalização como sendo um sequenciador textual, como já visto aqui, e na perspectiva da variação linguística, como veremos a seguir.

\section{Teoria da Variação Linguística}

A Sociolinguística Variacionista considera que características do falante são capazes de influir no seu modo de falar, sendo que tal influência foi atestada já em 1963 por William Labov (2008), em seu estudo realizado na ilha de Martha's Vineyard, litoral de Massachusetts. Contudo, o termo Sociolinguística surgiu apenas no ano seguinte, em um congresso organizado pelo linguista William Bright, na Universidade da Califórnia, em Los Angeles (UCLA). Nessa conferência, estavam presentes respeitáveis referenciais, como John Gumperz, William Labov, John Fisher e outros.

Em 1966, no texto "As dimensões da Sociolingüística", Bright define a nova área de estudo cujo objetivo consiste em "demonstrar a covariação sistemática das variações lingüística e social e, talvez, até mesmo demonstrar uma relação causal em uma ou outra direção" (1974, p. 17). Assim, para a Sociolinguística, a diversidade, ou a variação linguística, é sistemática e motivada por fatores estruturais e sociais (MOLLICA, 2008, p. 10). Posto isso, ressaltamos que a Sociolinguística vê a variação linguística como "uma qualidade constitutiva do fenômeno lingǘstico" (ALKMIN, 2005, p. 33), e não um defeito.

Assim, ela se preocupa com o "estudo da língua falada, observada, descrita e analisada em seu contexto social, isto é, em situações reais de uso" (p. 31), uma vez que

Linguagem e sociedade estão ligadas entre si de modo inquestionável. Mais do que isso, podemos afirmar que essa relação é a base da constituição do ser humano. A história da humanidade é a história de seres organizados em sociedades e detentores de um sistema de comunicação oral, ou seja, de uma língua (ALKMIN, 2005, p. 21).

Ressaltamos, portanto, que as comunidades linguísticas apresentam um caráter multifacetado (SILVA-CORVALÁN, 1989) e é justamente a heterogeneidade da língua o objeto de estudo da Sociolinguística (BRIGHT, 1974; SILVA-CORVALÁN, 1989; MORENO-FERNÁNDEZ, 1998; ALKMIN, 2005; CAMACHO, 2005; MOLLICA, 2008).

A variação linguística não é aleatória, mas sistemática e motivada por fatores linguísticos e não linguísticos. Dentre estes, destacamos as variações diacrônica, diatópica, diassexual, diageracional e diastrática.

A variação diacrônica, ou histórica, refere-se às mudanças ocorridas ao longo do tempo, as quais podem ocorrer nos diferentes níveis linguísticos, segundo explicam Ilari e Basso (2014). Como exemplo, o processo de gramaticalização e o processo inverso, a lexicalização. 
A variação diatópica, ou geográfica, conforme atesta Alkmin (2005), diz respeito às diferenças distribuídas no espaço físico. Assim como a variação diacrônica, a diatópica ocorre em diferentes níveis linguísticos, como as variações lexical, fonológica e morfossintática.

A análise sobre a variação diassexual deve considerar a organização social do contexto de fala, pois essa variável ilustra um cenário bastante interessante, visto que aponta "uma maior consciência feminina do status social das formas linguísticas" (PAIVA, 2008, p. 35). Nesse sentido, destacamos a relação existente entre sexo, variação linguística e o prestígio atribuído pela comunidade às variantes linguísticas, porquanto as mulheres tendem a estar à frente de processos de mudança linguística. Entretanto, faz-se indispensável considerar o valor social da variante inovadora, uma vez que a tendência é as mulheres implementarem, na língua, as formas socialmente prestigiadas; em contrapartida, assumem uma postura conservadora no que diz respeito às variantes desprestigiadas. Salientamos, portanto, que as mulheres tendem a preferir as variedades de maior prestígio, pois

quando se trata de implementar na língua uma forma socialmente prestigiada [...] as mulheres tendem a assumir a liderança da mudança. Ao contrário, quando se trata de implementar uma forma socialmente desprestigiada, as mulheres assumem uma atitude conservadora e os homens tomam a liderança do processo (PAIVA, 2008, p. 36).

Esse cenário reflete a organização sociocultural em que se espera da mulher o uso de uma linguagem mais adequada aos padrões.

Por sua vez, a variação diageracional pode apresentar indícios de mudança da língua. Nesse sentido, este trabalho respalda-se no estudo da mudança em tempo aparente, viés respaldado na teoria de que um falante adulto reflete o estado da língua adquirida quando ele tinha aproximadamente 15 anos de idade (NARO, 2008). Assim, a fala de uma pessoa com 60 anos representa a língua de 45 anos atrás, enquanto a fala de uma pessoa com 40 anos revela a língua de 25 anos atrás.

Já a variação diastrática refere-se à organização sociocultural dos falantes, ou seja, vincula-se a um conjunto de fatores relacionados à identidade dos falantes e à organização sociocultural da comunidade de fala.

A classe social pode ser mensurada por diversos vieses (MOLLICA, 2008); contudo, para este estudo, consideramos o nível de escolaridade como o marcador de classe social, uma vez que a escola é capaz de incutir modelos e padrões, atuando, dessa maneira, de forma eficaz no processo de mudança ou de manutenção linguística. A escola age na preservação de formas de prestígio frente às tendências de mudança e caracteriza-se como fonte para o conhecimento de padrões estéticos e morais consoante à conformidade de dizer e de escrever, como atesta Votre (2008).

Segundo o autor, essa variável atua em diferentes instâncias: 
A primeira é entre forma de prestígio social e forma relativamente neutra. A segunda distinção é entre o fenômeno socialmente estigmatizado e fenômeno imune à estigmatização. A terceira versa sobre os fenômenos que são objeto de ensino escolar e aqueles que escapam à atenção normativa da escola (p. 51).

A primeira distinção é estabelecida no status econômico e no prestígio social atribuído aos usuários de determinada variante. O prestígio social opõe-se ao desprestígio direcionado àqueles que não desfrutam do prestígio social e econômico. A forma de falar socialmente prestigiada é estabelecida a partir dos ditames da literatura oficial e das gramáticas normativas. A segunda divisão fundamenta-se no falar estigmatizado e no falar prestigiado; assim, o falar estigmatizado é alvo de rejeição. E, ainda, a terceira divisão volta-se aos fenômenos controlados pela escola, ou seja, a imposição da gramática normativa exercida pelo ambiente escolar, conforme explica Votre.

Considerando, pois, os tipos de variáveis investigadas na variação linguística, daremos destaque às variáveis diassexual, a qual apresentou maior evidência de uso do dai por parte das mulheres, diageracional e diastrática. Para este estudo, não vem ao caso a análise diatópica, já que os dados abordam apenas uma capital. Ressaltamos, entretanto, que os fatores condicionadores não agem de forma isolada, mas atuam em conjunto e são inter-relacionados.

\section{Lócus da Pesquisa}

A pesquisa conta com os dados coletados em Curitiba, capital paranaense, atualmente formada por oito distritos urbanos: Portão, Cidade Industrial, Pinheirinho, Bairro Novo, Cajuru, Boqueirão, Boa Vista e Santa Felicidade. Suas cidades limítrofes são Almirante Tamandaré, Colombo, Pinhais, São José dos Pinhais, Fazenda Rio Grande, Araucária, Campo Largo e Campo Magro. Segundo o IBGE (2019), Curitiba conta com 1.751.907 habitantes, sua unidade territorial é de 435,036 km², com o Índice de Desenvolvimento Humano Municipal (IDHM) de 0,823.

O município, centro econômico do estado, é considerado uma das melhores cidades do país para negócios. Altamente tecnológica e industrializada, não depende de atividades agroindustriais para movimentar sua economia. Apresenta ampla rede de préescolas, escolas de Ensino Fundamental e Médio, além de importantes instituições de ensino superior, como Universidade Federal do Paraná (UFPR), Universidade Tecnológica Federal do Paraná (UTFPR) e Pontifícia Universidade Católica do Paraná (PUCPR), caracterizando a capital como um polo de ensino superior.

\section{Procedimentos Metodológicos}

Este artigo conta com os dados do Projeto Atlas Linguístico do Brasil (ALiB). A iniciativa para a elaboração do Atlas Linguístico do Brasil ocorreu na Universidade 
Federal da Bahia, em 1996, por ocasião do Simpósio Caminhos e Perspectivas para a Geolinguística no Brasil. O Comitê Nacional do ALiB constitui-se da união de 16 universidades brasileiras, subdivididas em comitês responsáveis pelas atividades para o desenvolvimento do atlas. O Projeto contou com a participação de 1.100 informantes, espalhados pelos 8.515 .767 quilômetros de terras brasílicas percorridas pelas equipes de pesquisadores do Projeto ALiB.

A custo de curiosidade, destacamos o cenário brasileiro no que diz respeito à publicação dos volumes 1 e 2 do Atlas Linguístico do Brasil, realizada no ano de 2014, pela Universidade Estadual de Londrina (UEL). Ao concretizar a primeira publicação do trabalho de 18 anos do Comitê Nacional e das equipes regionais, o Atlas Linguístico do Brasil apresenta, a princípio, o volume I (CARDOSO et al., 2014a) com a introdução, história, metodologia, rede de pontos, questionários e informantes do Atlas Linguístico do Brasil, e o volume II (2014b), de cartas, com os resultados das 25 capitais brasileiras $^{5}$ em mapas linguísticos com dados fonéticos, morfossintáticos e semântico-lexicais. Está prevista a publicação do terceiro e do quarto volumes do $\mathrm{ALiB}$, que apresentarão o perfil mais amplo dos resultados, abordando toda a rede nacional.

Nosso corpus concentra-se em oito informantes da capital do estado paranaense cujos perfis obedecem às exigências do projeto $\mathrm{ALiB}$, sendo distribuídos equitativamente por duas faixas etárias - 18 a 30 anos e 50 a 65 anos -, entre homens e mulheres, alfabetizados, que cursaram o nível fundamental de ensino; nas capitais, acrescentam-se quatro informantes com nível superior de escolaridade (um homem e uma mulher de cada faixa etária).

O Quadro 1 apresenta o perfil dos informantes do ALiB nas capitais.

Quadro 1 - Perfil dos informantes (capitais)

\begin{tabular}{|c|c|c|c|}
\hline Informante & Escolaridade & Faixa Etária & Sexo \\
\hline $\mathbf{0 1}$ & Fundamental & I $(18$ a 30 anos $)$ & Masculino \\
\hline $\mathbf{0 2}$ & Fundamental & I $(18$ a 30 anos $)$ & Feminino \\
\hline $\mathbf{0 3}$ & Fundamental & I $(18$ a 30 anos $)$ & Masculino \\
\hline $\mathbf{0 4}$ & Fundamental & I $(18$ a 30 anos $)$ & Feminino \\
\hline $\mathbf{0 5}$ & Superior & II $(50$ a 65 anos $)$ & Masculino \\
\hline $\mathbf{0 6}$ & Superior & II $(50$ a 65 anos $)$ & Feminino \\
\hline $\mathbf{0 7}$ & Superior & II $(50$ a 65 anos $)$ & Masculino \\
\hline $\mathbf{0 8}$ & Superior & II $(50$ a 65 anos $)$ & Feminino \\
\hline
\end{tabular}

Fonte: Cardoso et al. (2014a).

\footnotetext{
${ }^{5}$ Brasília e Palmas não foram incluídas, pelas suas datas de criação.
} 
Para a análise do fenômeno estudado, observamos a sua realização em respostas aos Questionários Fonético-Fonológico (QFF), Semântico-Lexical (QSL) e Morfossintático (QMS) e aos Temas para Discursos Semidirigidos do questionário Projeto ALiB (COMITÊ NACIONAL..., 2001).

Como Temas para Discursos Semidirigidos temos:

1 Relato pessoal - Relate um acontecimento marcante em sua vida (casamento, namoro...).

2 Comentário - De que programas de televisão você/ o (a) senhor (a) gosta mais? Por quê?

3 Descrição - Você/ o (a) senhor (a) trabalha em quê? Fale um pouco sobre seu trabalho.

4 Relato não pessoal -Conte um caso/ um fato de seu conhecimento (de que tenha ouvido falar, que tenha acontecido com um amigo, etc.).

Constituído a partir de todas as ocorrências do daí como resposta dada aos Questionários Fonético-Fonológico (QFF), Semântico-Lexical (QSL) e Morfossintático (QMS) e aos Temas para discursos semidirigidos, este estudo considera diferentes níveis de monitoramento da fala, isto é, desde um discurso menos monitorado no discurso semidirigido até o mais monitorado, nas respostas ao QFF.

Os dados foram quantificados de acordo com a Teoria da Variação Linguística, ou seja, consideramos os dados linguísticos da fala de homens e de mulheres, estratificados em duas faixas etárias (cf. Quadro 1) e com níveis de escolaridades distintos. O corpus corresponde aos dados do Projeto $\mathrm{ALiB}$, no qual procedemos às seguintes etapas: i) primeiro, realizamos a coleta de dados por meio dos áudios disponibilizados pelo Projeto, utilizando o programa Winamp para rodar as gravações; ii) na sequência, conferimos os áudios com as transcrições e coletamos o nosso objeto de estudo, ou seja, o item lexical dai; iii) utilizamos, como forma de organizar os dados, a planilha do Microsoft Excel 2013, espaço no qual selecionamos as variantes de acordo com o perfil do informante procedimento importante para a contagem dos dados e melhor visualização dos resultados -; e, por fim, após a coleta e a organização dos dados, passamos para iv) produção dos gráficos de acordo com a variáveis trabalhadas, levando em consideração o sexo, a escolaridade e a idade dos informantes.

\section{Descrição e Análise dos Dados}

A descrição e análise de dados divide-se em duas etapas: os dados segundo os microdomínios e, em seguida, segundo as variáveis sociais. 


\section{Os Dados Sob a Visão dos Microdomínios}

Neste artigo, os dados sob a visão dos microdomínios apresentam-se com um caráter mais descritivo e, para tanto, adotamos os conceitos de Tavares (2006) no que se refere aos cinco microdomínios: (i) sequenciação textual: estratégia coesiva que assinala a ordem pela qual as unidades conectadas sucedem-se ao longo do tempo discursivo; (ii) sequenciação temporal: informações introduzidas que se sucedem temporalmente em relação às informações já dadas; (iii) introdução de efeito: informações introduzidas que representam consequência ou conclusão em relação ao que foi dito previamente; (iv) retomada: movimento de recuperação do fluxo temático anterior, interrompido por uma digressão; e (v) finalização: sinalização do final do tópico/assunto em andamento. Exemplificaremos tais conceitos com os dados do corpus para facilitar o entendimento de cada um:

(1) INQ.- Nossa! Vocês nasceram pertinho uns do outro, né?

INF.- É. (risos). Vinte sete, meu irmão tem vinte e quato, eu tenho vinte e um, $D A I I$ vem,

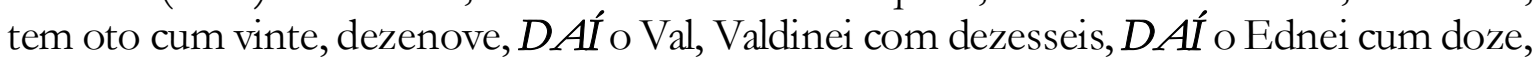
e o Júnior cum nove (Curitiba, informante 1).

(2) INF.- (risos) Ah, é simples. Ah, torta de maçã tem que fazê aquela massa, né, tipo a de empadão. $D A \hat{I} . .$. faiz... faiz... tipo assim na massa, da, da, pra torta, né, eu uso trigo, duas colheres de margarina, meia de... de... meia xícara de leite, uma pitada, uma meia, uma meia colher de açúcar e bate bem ela, tipo assim, mexo bastante, sabe? dois ovos, até ela ficá aquela massa consiten... consistente, que $D A I ́$ vai espalhá. E $D A I ́$, eu faço... o recheio, né? Que é maçã. Coloco a maçã... primero eu bato a maçã, né? Que... depois, depois coloca a maçã, aqueles pedaços que a gente vê, né (Curitiba, informante 1).

Em (1), o elemento em estudo pode ser considerado dentro do microdomínio de (a) sequenciação textual: no primeiro momento, dai antecede o verbo vir no presente do indicativo (vem). Assim, podemos associar o item à função de advérbio, pois está "direcionando" o verbo; porém não podemos afirmar que a posição em que o daí se encontra seja a de advérbio, por não estar modificando o verbo. As duas ocorrências seguintes do dai podem ser interpretadas como unidades conectadas que se sucedem ao longo do tempo discursivo.

Nas três ocorrências do daí, no exemplo (2), verificamos que a primeira indica a sequência do texto, em que o informante está explicando/ensinando como fazer uma receita; portanto, a primeira vez que a unidade lexical aparece está assinalando a ordem das unidades conectadas. No segundo momento, o termo aparece com sentido de introdução de efeito - as informações introduzidas representam consequência ou conclusão em relação ao que foi dito previamente. Vejamos: "até ela ficá aquela massa consiten... consistente, que daí vai espalhá". A consequência de a massa espalhar é por 
estar consistente. Notamos que o emprego do daí realmente introduziu efeito ao discurso da informante. E, no terceiro caso, o daí funciona como sequenciador textual.

O emprego do daí nas funções de retomada e de finalização pode ser observado nas sequências discursivas 3, 4, 5 e 6:

\section{(3) INQ.- Senac?}

INF.- Num é. Num é, num tem nada a vê de sési. É, é um... é, tipo assim, uma casa mesmo, sabe, que ensina. Então, isso $D A I ́$ foi a... foi o meu patrão que me colocô lá, que eu falei pra ele que eu, que eu quero... num nasci pá sê... pá trabalhá em escritório (Curitiba, informante 1).

(4) INQ.- Quando uma criança está dormindo e não se quer acordar, a gente diz: "Fale baixo, não faça...”?

INF.- Não faça barulho, que se não vai acordá a criança, né. $D A I ́$ acorda reinando, né (Curitiba, informante 3).

(5) INQ.- Tem alguma coisa aí né ?

INF.- Canoa cê... cê vai no... aliás, o bote, o bote vai no remo, né, e a canoa, motor. É chamado praticamente... geralmente ele é chamado de bote, né, mas muitos já falam... canoa, canoa no caso seria um bote maior, né, que um bote já é peque...é uma estrutura menor, é pequeno, né, que vai fácil no remo, e a canoa já é maior, então... o documento é o motor $D A I ́$, né (Curitiba, informante 3).

(6) INF.- Médio, nem alto nem baixo.

INQ.- Porquê?

INF.- Ah, pra não incomodá os vizinho, né, alto e baxo a gente também num dá nem pra escutá $D A I ́$ né (Curitiba, informante 4).

Em (3) e (4), temos o daí como retomada, exercendo uma função de recuperação do que foi dito anteriormente: "É, é um... é, tipo assim, uma casa mesmo, sabe, que ensina. Então, isso daí foi a... foi o meu patrão que me colocô lá”. A retomada que o daí representa na oração é para reforçar que foi em uma casa, e não no SESI, que ele aprendeu a culinária. Quando o informante diz "Então, isso daí...", ele está retomando o que disse anteriormente, afirmando e atestando esse já dito de maneira a englobar todas as informações já mencionadas na fala, ou seja, o daí, nesse caso, encapsula os dados já ditos, como uma espécie de "caixa" em que se guardam informações de forma resumida, possibilitando que um trecho precedente do texto possa ser condensado, concentrado e retomado por meio de uma única expressão que se torna seu referente: isso daí, sendo que o pronome demonstrativo isso auxilia nesse processo.

No exemplo (4), a expressão pode ser compreendida como introdução de efeito, isto é, fazer barulho trará como consequência a criança acordar.

Já a finalização está exemplificada nos excertos (5) e (6): tanto em um quanto em outro o dai antecede o né. Poderíamos dizer que os dois são recursos da fala, porém, os 
interpretamos como inseridos no microdomínio de finalização, pois está concluindo o discurso do falante e afirmando, ou interagindo, com o receptor para que concorde ou discorde de sua afirmação, reforçada pelo né.

Os conceitos de Tavares (2002) são eficazes na análise da expressão. À primeira vista, o dai poderia ser facilmente denominado como conector, porquanto, na maioria das ocorrências, o termo conecta as orações. Embora essa denominação ainda não tenha sido estabelecida pela Gramática Normativa, a sua frequência na fala proporcionará a gradativa gramaticalização do daí.

Depois de analisadas as 492 ocorrências do dá, sob a ótica dos cinco microdomínios propostos por Tavares (2002), verificamos a atuação dos fatores sexo, faixa etária e escolaridade sobre o número de ocorrências, e não sobre a frequência das funções.

\section{Os Dados Sob a Ótica dos Fatores Extralinguísticos}

Além da análise do daí segundo a perspectiva dos macrodomínios, voltamo-nos à observação do fenômeno mediante as variáveis sociais a partir da perspectiva da Teoria da Variação Linguística. Nesse sentido, analisamos em que medida as variáveis sexo, faixa etária e escolaridade podem influenciar na produtividade de sequências discursivas com o daí.

Ressaltamos que, de acordo com a análise, o uso do dai é mais frequente na fala das mulheres de ambas as faixas etárias e escolaridades; sendo assim, optamos por apresentar os gráficos 2 e 3 abordando tal preferência. Como consequência, elaboramos um gráfico para a variável diassexual, um para a variável diageracional e um para a variável diastrática, com a exposição dos sexos, a fim de reforçar a maior preferência da variante na fala feminina em todos os níveis de variáveis.

Ao todo, contabilizamos 492 ocorrências de dai e iniciamos a nossa análise segundo a variável sexo, a qual é apresentada no Gráfico 1.

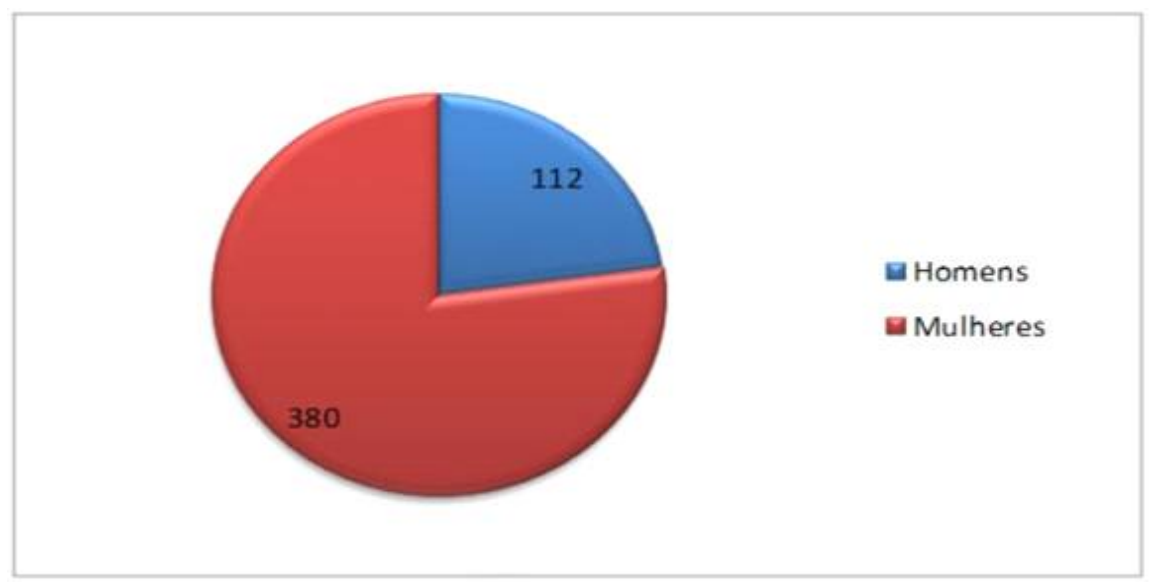

Fonte: Banco de dados do ALiB.

Gráfico 1 - Número de ocorrências do daí segundo a variável diassexual 
No Gráfico 1, apresentamos os dados segundo a variável sexo. Observamos que as mulheres realizaram 380 ocorrências, enquanto os homens, 112. Esse contexto possibilita afirmar que o uso do dai é muito mais recorrente na fala dos informantes do sexo feminino, podendo ser considerado um marcador da fala feminina das informantes de Curitiba. Nesse sentido, destacamos que a análise da variação entre sexo e variação linguística reflete um cenário pertinente devido à organização social do cenário em que a fala está inserida. Ao considerarmos a afirmação de Paiva (2008), de que o falar das mulheres se direciona ao status atribuído à forma, podemos considerar determinado prestígio à expressão daí nas expressões faladas, além de possibilitar uma afirmação de que a expressão está, paulatinamente, ganhando espaço em um processo de mudança linguística, isto é, de sua inclusão. Essa construção sociocultural é preconizada por construções em que se esperam, da mulher, uma linguagem mais adequada e direcionada aos padrões.

Destacamos que o item ocorreu nas respostas aos questionários mais controlados, o Fonético-Fonológico (QFF) e o Semântico-Lexical (QSL), mas se apresentou muito mais produtivo nos Temas para Discursos Semidirigidos, isto é, em uma modalidade do discurso mais informal e, por isso, menos monitorada, sendo utilizado nas funções do microdomínio da sequenciação.

$\mathrm{Na}$ sequência, cruzamos os dados considerando a faixa etária e o sexo dos informantes, conforme ilustra o Gráfico 2.

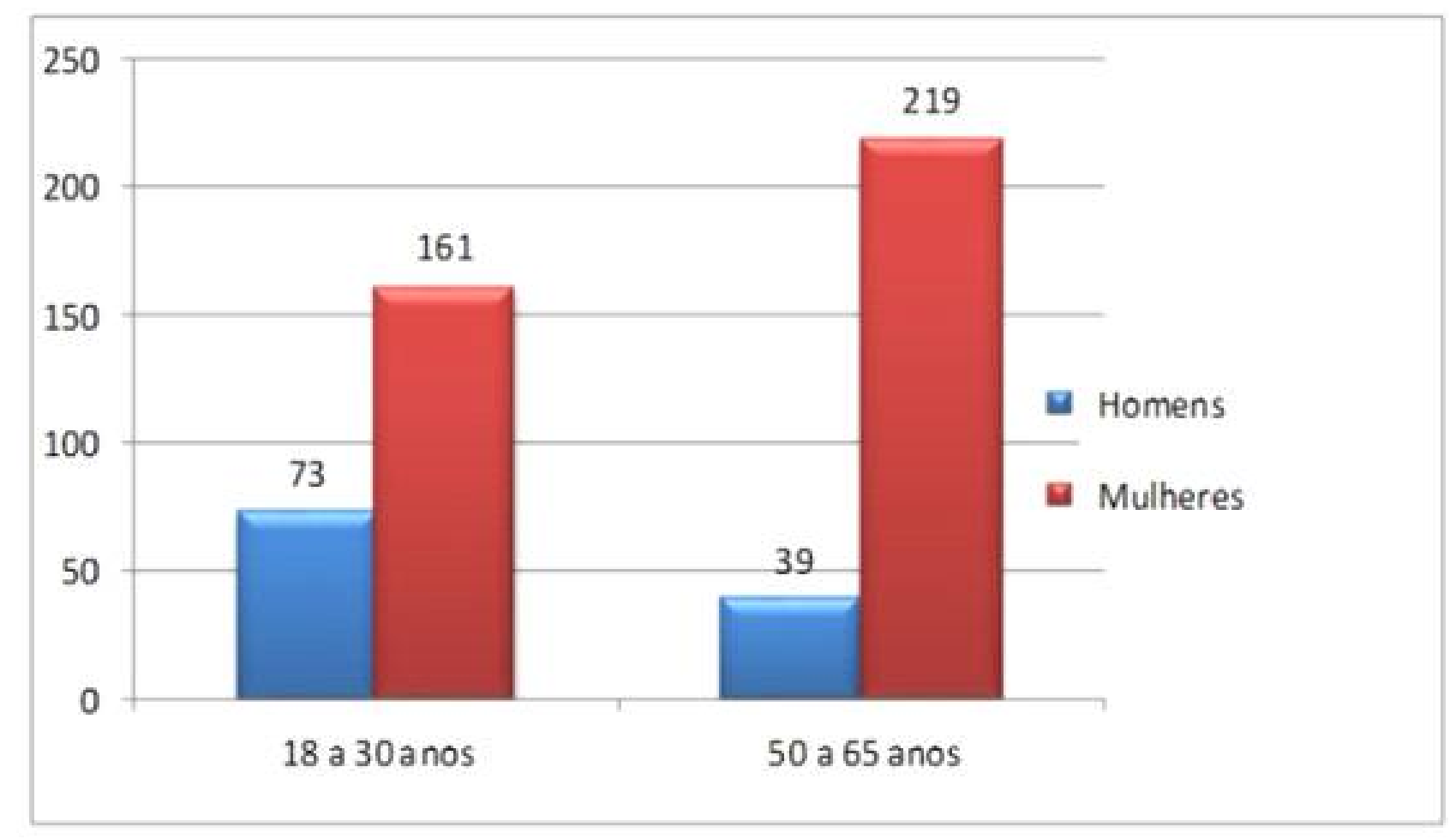

Fonte: Banco de dados do ALiB

Gráfico 2 - Número de ocorrências do daí segundo as variáveis diassexual e diageracional 
Computando os números absolutos, temos 73 realizações de daí na fala dos homens jovens e 161 na fala das mulheres jovens, o que dá uma diferença significativa entre os grupos, pois, dos 234 registros, os homens realizaram apenas $31,2 \%$ de daí, ao passo que as mulheres jovens o realizaram em 68,8\% dos casos. Se, ao contrário, computarmos os dados da segunda faixa etária, para os homens teremos 39 realizações, e para as mulheres, 219, mais uma vez demonstrando a predominância do item dai na fala das mulheres, visto que, na faixa etária II, encontramos $84,9 \%$, ao contrário da presença pouco significativa na fala dos homens da mesma faixa etária, com 15,1\%.

Nesse sentido, podemos verificar que a realização do daí está muito mais condicionada à variável sexo do que à variável faixa etária. Entretanto, assinalamos que a diferença entre a realização de homens e mulheres na faixa etária I, com 88 realizações, é menor do que em comparação à faixa etária II, com 180 realizações. Esse cenário possibilita inferirmos que a expressão daí vem ganhando espaço, paulatinamente, na fala dos informantes.

A próxima etapa diz respeito à análise da influência das variáveis sexo e escolaridade sobre o uso do daí, conforme apresenta o Gráfico 3.

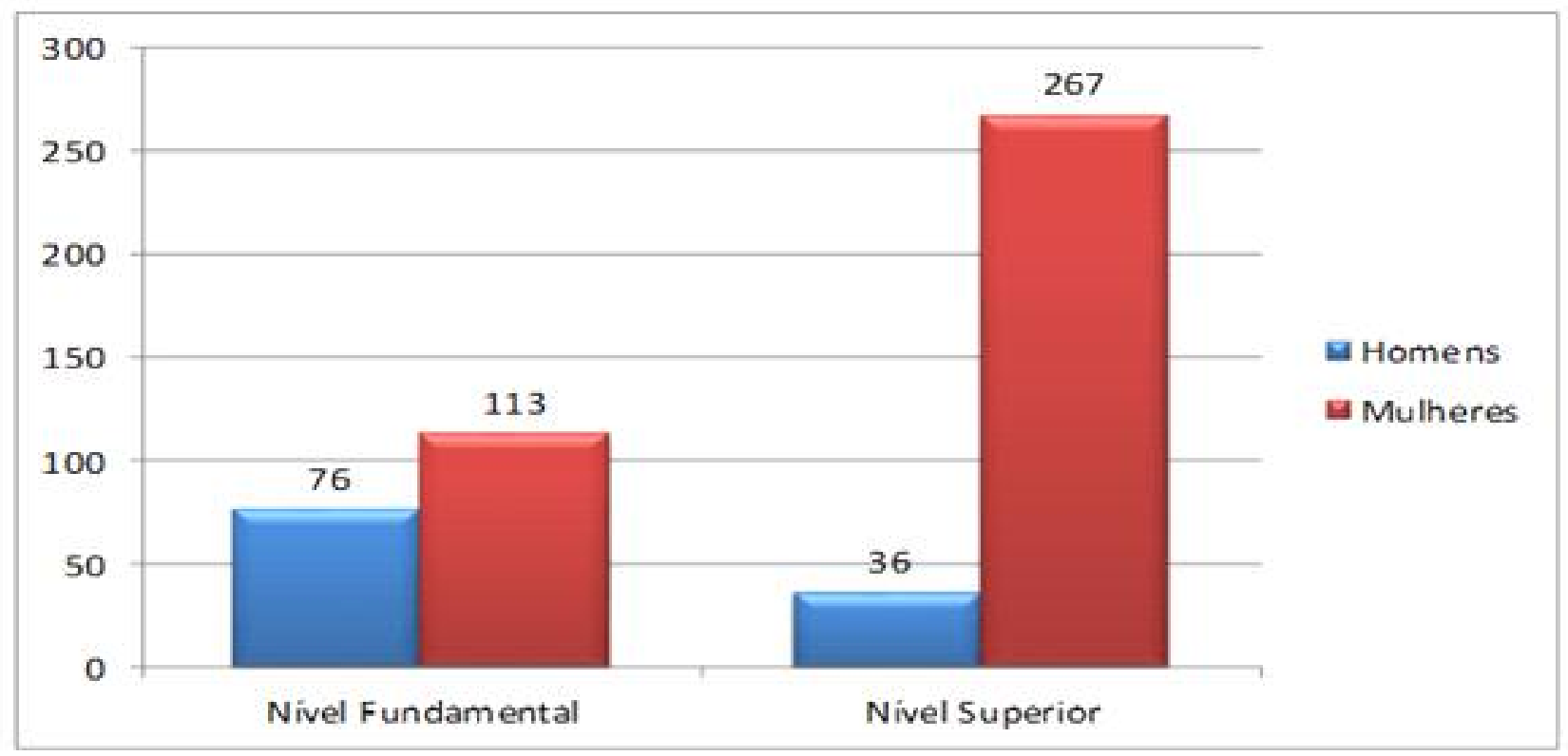

Fonte: Banco de dados do ALiB.

Gráfico 3 - Número de ocorrências do dai segundo a variável diassexual e diastrática

Analisando os dados do Gráfico 3, observamos que as mulheres de nível superior apresentam uma alta frequência de uso do dai: 267 realizações, enquanto os homens com o mesmo nível de escolaridade registram apenas 36 ocorrências. Quando se cruzam as variáveis sexo e escolaridade, as mulheres do Ensino Fundamental também lideram o uso de dai, com 113 registros, ao passo que na fala dos homens desse mesmo nível 
obtivemos 76 registros, resultados mais próximos entre si do que entre os informantes de ensino superior.

Dessa forma, destacamos que a realização do dai apresenta um cenário interessante quando observado o cruzamento da variável escolaridade e a variável sexo, visto que a diferença na fala dos informantes de nível fundamental apresenta apenas 37 ocorrências, ao passo que a diferença entre os informantes do nível superior é de 231 realizações. Esse cenário permite inferirmos que as mulheres com nível de escolaridade superior apresentam os maiores indicativos de realização do fenômeno, carregando a marcação de realização dotada de prestígio linguístico.

\section{Considerações Finais}

O estudo demonstrou que a expressão daí pode ser empregada com vários significados, dependendo do contexto em que elas estão inscritas. Limitá-las como apenas advérbio de tempo, como fazem as gramáticas normativas, não seria o adequado ou a única função de dai na fala, ou seja, compreendemos que a expressão assume uma característica polissêmica, dependendo da situação em que está sendo empregada; dessa forma, pudemos associar os sentidos de dai com base na noção de sequenciadores textuais (TAVARES, 2006), como explicado em análise.

Além dos conceitos de Tavares, há outras teorias que explicam os vários sentidos presentes no léxico. Uma delas é o conceito de contexto aplicado ao significado, exposto por Stephen Ullmann (1964), em que apresenta, como forma de embasamento, as ideias de Malinowski:

A concepção de contexto deve ultrapassar os limites da mera lingǘstica e transportar-se para a análise das condições gerais em que uma língua é falada... O estudo de qualquer língua, falada por um povo que vive em condições diferentes das nossas e possui uma cultura diferente, deve ser conduzido simultâneamente com o estudo da sua cultura e do meio ambiente (p. 106).

E também as de Wittgenstein: "Não se limita a dizer que podemos estabelecer o significado de uma palavra pela observação do seu uso; afirma corajosamente que o significado de uma palavra é o seu uso" (p. 135).

O significado das palavras também depende das influências sofridas de acordo com o contexto em que é empregado, ou seja, na concepção do autor, as palavras extraem do contexto certos determinantes que só farão sentido se estiverem em situações específicas de uso. Ullmann exemplifica o fato afirmando que "até os nomes próprios, as mais concretas de todas as palavras, têm uma variedade de aspectos dos quais um só será apropriado para uma situação particular” (p. 109). As ideias de Wittgenstein e Malinowski, endossadas por Ullmann, apresentam a relação do significado da palavra e sua dependência com o uso. 
Desta forma, interpretamos que o daí, além de ser caracterizado no microdomínio da sequenciação, empregando várias funções dentro do discurso da fala curitibana, o que representa o uso e suas várias possiblidades de sentido, pode servir de base para outros estudos com o objetivo de identificar marcas na fala de homens e de mulheres.

A partir da análise segundo as variáveis sociais, observamos que as mulheres realizaram 380 ocorrências de daí, enquanto os homens apenas 112, cenário que possibilita a afirmação de que o uso do dai é muito mais recorrente na fala dos informantes do sexo feminino, podendo ser considerado um marcador da fala feminina de Curitiba.

Ao considerarmos o cruzamento das variáveis diassexual e diastrática, encontramos, na faixa etária I, dos mais jovens, 73 realizações de daí na fala dos homens e 161 na fala das mulheres, computando uma diferença significativa. De modo semelhante, na faixa etária II temos, para os homens, 39 realizações, e para as mulheres, 219, corroborando a predominância do item dai na fala das mulheres. Ainda, observamos que as mulheres de nível superior apresentam uma alta frequência de uso de daí, 267 realizações, enquanto os homens com o mesmo nível de escolaridade realizaram apenas 36 ocorrências.

Dessa forma, podemos considerar o daí como marca discursiva na fala de mulheres da faixa etária II, com nível superior de escolaridade, o que pode indicar que a mudança não se consolidou, mas a frequência do seu uso permanece no nível da variação diagenérica e diastrática.

Tendo em vista os estilos de fala, podemos afirmar que as ocorrências de daí no corpus foram registradas tanto no estilo espontâneo (temas para discursos semidirigidos) como no estilo mais controlado (de perguntas e respostas), com predominância no estilo espontâneo. Esse cenário se deve, especialmente, à modalidade menos rígida de discurso.

\section{REFERÊNCIAS}

ALKMIN, T. M. Sociolingüística. In: MUSSALIM, F.; BENTES, A. C. Introducão à lingüística: domínios e fronteiras. 5. ed. São Paulo: Cortez, 2005. p. 21-47.

BRIGHT, W. As dimensões da sociolingüística. In: FONSECA, M. S. V.; NEVES, M. F. (Org.). Sociolingüística. Rio de Janeiro: Eldorado, 1974. p. 17-24.

CAMACHO, R. G. Sociolingüística parte II. In: MUSSALIM, F.; BENTES, A. C. Introdução à lingüística: domínios e fronteiras. 5. ed. São Paulo: Cortez, 2005. p. 49-75.

CARDOSO, S. A. M. O Projeto ALiB e sua trajetória. In: MOTA, J. A.; CARDOSO, S. A. M. (Org.). Documentos 2: Projeto Atlas Lingüístico do Brasil. Salvador: Quarteto, 2006. p. 27-34. 
CARDOSO, S. et al. Atlas Linguístico do Brasil. Introdução. Londrina: EDUEL, 2014a. v. 1.

CARDOSO, S. et al. Atlas linguístico do Brasil. Cartas linguísticas 1. Londrina EDUEL, 2014b. v. 2.

CASTILHO, A. A gramaticalização. Estudos Lingüisticos e Literários, Salvador, n. 19, p. 25-63, mar. 1997a.

CASTILHO, A. Língua falada e gramaticalização. Filologia e Lingüistica Portuguesa, n. 1, p. 107-120, 1997b.

COMITÊ NACIONAL DO PROJETO ALiB. Atlas Lingüistico do Brasil: questionários 2001. Londrina: Ed. da UEL, 2001.

CUNHA, A. G. da. Dicionário Etimológico Nova Fronteira da Lingua Portuguesa. 2. ed. Rio de Janeiro: Nova Fronteira, 1994.

FERREIRA, A. B. de H. Novo dicionário de Lingua Portuguesa. 2. ed. Rio de Janeiro: Nova Fronteira, 1986.

GONÇALVES, S. C. L.; LIMA-HERNANDES, M. C.; CASSEB-GALVÃO, V. C. (Org.). Introdução à gramaticalização: princípios teóricos e aplicação. São Paulo: Parábola, 2007.

IBGE Cidades. Curitiba. Disponível em: https://bit.ly/2ZUeoAwCTBA. Acesso em: 12 jun. 2019.

ILARI, R.; BASSO, R. O português da gente: a língua que estudamos, a língua que falamos. 2. ed. São Paulo: Contexto, 2014.

KOCH, I. V. A inter-ação pela linguagem. 11. ed. São Paulo: Contexto, 2015.

LABOV, W. Padrões sociolinguísticos. Tradução de Marcos Bagno, Maria Marta Pereira Scherre e Caroline Rodrigues Cardoso. São Paulo: Parábola, 2008 [1972].

LOPES, C. Gramaticalização: definição, princípios e análise de casos. Niterói: EDUFF, 2008.

MOLLICA, M. C. Fundamentação teórica: conceituação e delimitação. In: MOLLICA, M. C.; BRAGA, M. L. (Org.). Introdução à Sociolinguïstica: o tratamento da variação. São Paulo: Contexto, 2008. p. 9-14.

MORENO-FERNÁNDEZ, F. Princípios de sociolingüística y sociologia del lenguaje. Barcelona: Ariel, 1998. 
NARO, A. J. Modelos quantitativos e tratamento estatístico. In: MOLLICA, M. C.; BRAGA, M. L. (Org.). Introducão à Sociolingïística: o tratamento da variação. São Paulo: Contexto, 2008. p. 15-25.

PAIVA, Maria da Conceição. A variável gênero/sexo. In: MOLLICA, M. C.; BRAGA, M. L. (Org.). Introdução à Sociolingüística: o tratamento da variação. São Paulo: Contexto, 2008. p. 33-42.

SANTOS, C. D. dos. Marcadores discursivos nas entrevistas retextualizadas. In: STORTO, L. J.; NAKAYAMA, J. K.; BURGO, V. H. Texto, contexto e discurso: homenagem a Paulo de Tarso Galembeck. Curitiba: Appris, 2014. p. 187-209.

SAUSSURE, Ferdinand. Curso de lingüistica geral. 26. ed. Tradução de Antônio Chelini, José Paulo Paes e Izidoro Blikstein. São Paulo: Cultrix: 1995.

SILVA-CORVALÁN, C. Sociolingüistica: teoría y análisis. Madrid: Alhambra Universidad, 1989.

TAVARES, M. A. Daí (veio) o uso do daí na codificação lingüística da articulação discursiva. Working Papers em Lingüistica, n. 6, p. 92-115, 2002.

TAVARES, M. A. Abordagem pancrônica à gramaticalização de daí como conector. Signum: Estudos da Linguagem, Londrina, n. 9, v. 2, p. 245-271, dez. 2006. Disponível em: https://bit.ly/2BkuqcKSigTav.

ULLMANN, S. Semântica. Uma introdução à ciência do significado. 5. ed. Tradução de J. A. Osório Mateus. Lisboa: Fundação Calouste Gulbenkian, 1964.

VITRAL, L. A forma CÊ e a noção de gramaticalização. Revista Estudos da Linguagem, Belo Horizonte, v. 1, n. 4, p. 115-124, jan./jun. 1996.

VOTRE, S. J. Relevância da variável escolaridade. In: MOLLICA, M. C.; BRAGA, M. L. (Org.). Introdução à Sociolinguiústica: o tratamento da variação. São Paulo: Contexto, 2008. p. 51-57. 